\title{
Letter
}

\section{Does Health Vulnerability Predict Voting for Right-Wing Populist Parties in Europe?}

\author{
NOLAN M. KAVANAGH University of Pennsylvania \\ ANIL MENON University of Michigan \\ JUSTIN E. HEINZE University of Michigan
}

$W$ hy do voters in developed democracies support right-wing populist parties? Existing research focuses on economic and cultural vulnerability as driving this phenomenon. We hypothesize that perceptions of personal health vulnerability might have a similar influence on voters. To test this argument, we analyzed all waves of the European Social Survey (2002-2020). Our findings suggest that voters with worse self-reported health were significantly more likely to vote for right-wing populist parties. The relationship persists even after accounting for measures of cultural and economic vulnerability, as well as voters' satisfaction with both their personal lives and their country's health system. The influence of health on support for right-wing populist parties appears to be greater than that of income and self-reported economic insecurity, while less than that of gender and attitudes about immigrants. Our findings suggest that policies affecting public health could shape not only health outcomes but also the political landscape.

\section{INTRODUCTION}

$\mathbf{R}$ ight-wing populist parties are surging in support across the Western world (Norris and Inglehart 2019). Why do voters in developed democracies support such parties? A growing body of research has identified economic insecurity and cultural backlash as potential drivers of recent populist successes (Algan et al. 2017; Hochschild 2016; Inglehart and Norris 2016; Mudde 2007; Oesch 2008; Rodrik 2018; Smith and Hanley 2018). According to these explanations, once-dominant socioeconomic groups perceive an erosion of their economic opportunities or a threat to their privileged positions in society. These threats heighten voters' perceived vulnerability, motivating them to support parties that promise to restore their socioeconomic standing through antimulticulturalism, antiglobalism, and anti-immigration (Inglehart and Norris 2016).

We argue that a voter's perceived health may meaningfully contribute to populist support via a similar mechanism. The development of illness and disability often produces frustration with one's physical and

\footnotetext{
Nolan M. Kavanagh (D), Medical student, Perelman School of Medicine, University of Pennsylvania; Lecturer, Department of Periodontics and Oral Medicine, School of Dentistry, University of Michigan, nolan.kavanagh@pennmedicine.upenn.edu.

Anil Menon (D), PhD candidate, Department of Political Science, University of Michigan, armenon@umich.edu.

Justin E. Heinze (ID), Assistant Professor, Department of Health Behavior and Health Education, School of Public Health, University of Michigan,jheinze@umich.edu.
}

Received: June 26, 2020; revised: February 27, 2021; accepted: March 23, 2021. First published online: April 26, 2021. emotional limitations, and it prompts people to compare themselves with their healthier neighbors (Buunk, Gibbons, and Buunk 2013; Martz and Livneh 2007). This experience may increase an individual's sense of personal vulnerability regardless of their socioeconomic background. They may then blame their misfortunes on the political establishment as the architects of existing social, political, and economic structures (Laclau 2005; Nussbaum 2018). If true, individuals who suffer poorer health and more disability would be desirous of changing the political status quo. This desire for structural change would, in turn, draw them toward parties that campaign for a fundamental restructuring of a "biased and broken" system.

As such, health-related vulnerability may contribute to an antiestablishment sentiment alongside economic and cultural drivers of populism. Indeed, some research has associated declining population health with rightwing populist voting. U.S. counties that experienced the greatest rise in mortality over recent decades, especially among whites, were most likely to vote for President Trump and shift toward the Republican Party in 2016 (Bilal, Knapp, and Cooper 2018; Bor 2017). Similar associations have been shown for rates of chronic opioid use (Goodwin et al. 2018) and other markers of poor public health (Wasfy, Stewart, and Bhambhani 2017). In the U.K., localities that experienced greater rises in "deaths of despair" due to suicide or drug overdose in the previous decade were more likely to vote for Brexit (Koltai et al. 2019). However, the relationship between poor health and right-wing populist voting remains to be demonstrated at the individual level with appropriate controls for economic and cultural vulnerability.

Understanding how poor health influences right-wing populist support could have important implications for 
policy makers. It suggests that illness may counterintuitively increase support for political parties that seek to dismantle medical and public health services (Pavolini et al. 2018). It could also enrich our understanding of the connection between health and political participation (Gollust and Haselswerdt 2019). Existing work has documented how, for example, people with disabilities, more depressive symptoms, and poorer self-reported health are less likely to vote (Landwehr and Ojeda 2021; Pacheco and Fletcher 2015; Schur et al. 2002). We hypothesize that perceived health vulnerability may influence a voter's decision in the polling booth itself. To test this argument, we explore whether an individual's health vulnerability, as operationalized by their self-reported health, predicts their support for right-wing populist parties.

\section{METHODS}

\section{Sample}

We pooled all available waves of the European Social Survey (ESS), collected from 2002 through early 2020. The survey measures social, political, and other attitudes and behaviors across Europe. Respondents were included in our main analyses if they stated the political party for which they voted in their country's last national elections and their subjective general health. Cases were weighted using the ESS's poststratification weights, which correct for sampling errors and nonresponse rates within each country to reduce selection bias. In total, our main analyses included 188,478 weighted cases across 24 countries, based on 192,896 unweighted cases.

\section{Variable Preparation}

Our analyses focus on right-wing populist support because most populist parties in Europe embrace this ideology. Respondents were coded as having voted for either a right-wing populist party or another party in their country's last national elections. The list of rightwing populist parties was taken from Inglehart and Norris (2016) and Norris and Inglehart (2019). All other parties were coded as mainstream, including the two leftwing populist parties, Podemos of Spain, and Syriza of Greece. The ESS captured too few of their voters to empirically test whether self-reported health drives leftwing populist support. If, for a given round of the ESS, a party was grouped under the category "Other," we coded it as mainstream because we could not distinguish it from other parties. In a few instances, this aggregation misclassified some right-wing populist voters as mainstream; however, any resulting classification errors should bias against finding support for our hypothesis.

The specifications of our models align with those of previous analyses of right-wing populist voting (Inglehart and Norris 2016; Oesch 2008). We included controls for demographics (age, gender, years of formal education, religiosity, and being an ethnic minority), socioeconomics (Goldthorpe occupation scheme [Goldthorpe,
Llewellyn, and Payne 1980], income decile within one's country, self-reported economic insecurity, being on government benefits, having been unemployed for 3+ months, and rurality of domicile), and cultural attitudes (negative attitudes about immigrants, mistrust in national institutions, mistrust in international institutions, espousing authoritarian values, and degree of right-wing selfplacement), as well as fixed effects for country (to adjust for differences in standard of living and evaluation of health across the countries in our sample) and survey year (to account for differences in the general political climate within Europe across years). To ensure that health status did not simply reflect general quality of life, we controlled for satisfaction with life as a whole. To account for negative health care experiences, we controlled for satisfaction with a country's health system. The inclusion of potential posttreatment variables - that is, variables that might be affected by health status - could bias the observed association between health and rightwing populist voting. To address this concern, we provide results from the sequential introduction of variables to our models as a robustness check in the appendix.

We operationalized health vulnerability using two continuous self-reported health measures: (1) subjective general health, which the ESS elicited from respondents on a five-point scale ranging from "very good" to "very bad," and (2) being hampered in daily activities by illness, disability, mental health problems, or other infirmities, measured on a three-point scale from "none" to "a lot." Full details on all variables and reliability analyses of scales are provided in the appendix.

\section{Statistical Analyses}

Missing observations were multiply imputed for variables other than voting and subjective general health using a bootstrapping-based algorithm with five imputations. We tested the relationship between health and voting using binomial logistic regressions on poststratificationweighted cases. Full details, tables, and robustness analyses are provided in the appendix.

\section{RESULTS}

Between 2002 and 2020, 13\% of respondents voted for right-wing populist parties. With respect to subjective general health, $22 \%$ of voters reported "very good" health, 44\% "good," 26\% "fair," 6\% "bad," and 1\% "very bad." With respect to being hampered by health problems, $73 \%$ of voters reported "no" limitations, $21 \%$ were limited "to some extent," and 6\% "a lot."

We find that Europeans with worse self-reported health were more likely to vote for right-wing populist parties between 2002 and 2020 (Figure 1). We examined this relationship using both measures of selfreported health. After controlling for demographics, socioeconomics, cultural attitudes, and more, a voter who rated their health as "very bad" had $26 \%$ greater odds of voting for a right-wing populist party than someone who responded as "very good" (Model 1; 
FIGURE 1. Unadjusted Percentage of Right-Wing Populist Voters by Health Status across Europe from 2002-2020

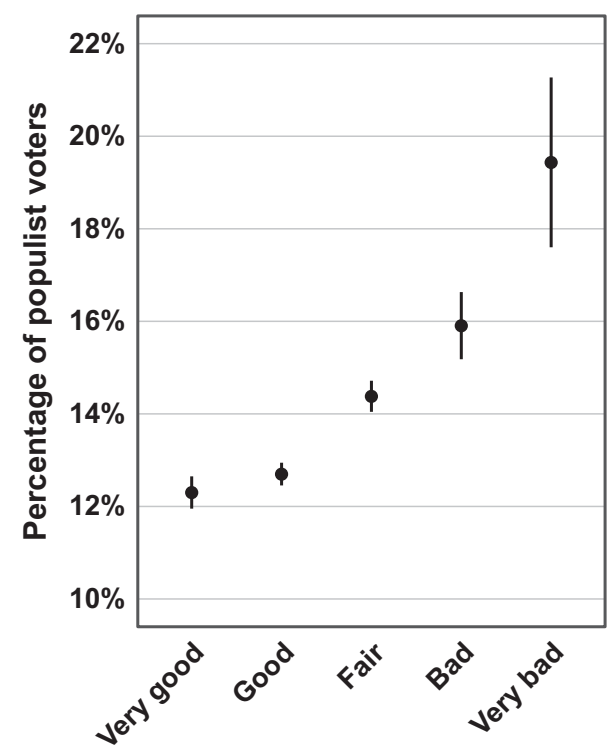

Subjective general health

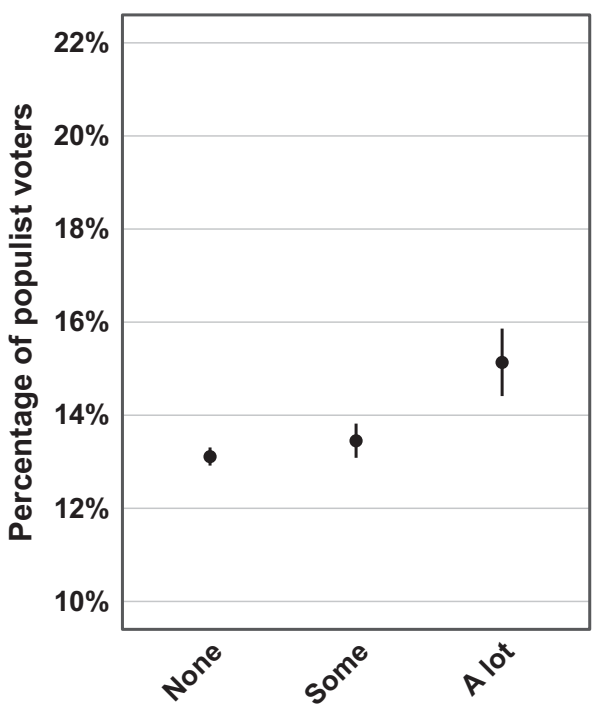

Hampered by disability, etc.

Note: Percentages are weighted by the ESS's poststratification weights. Black bars denote $95 \%$ confidence intervals. Estimates are not adjusted for other predictors of right-wing populist voting.

TABLE 1. Adjusted Association between Self-Reported Health and Voting for Right-Wing Populist Parties across Europe from 2002-2020

\begin{tabular}{|c|c|c|c|}
\hline & Model 1 & Model 2 & Model 3 \\
\hline Subjective general health & $\begin{array}{c}1.059 \\
(1.034 \text { to } 1.084) \\
p<0.001\end{array}$ & Not included & $\begin{array}{c}1.046 \\
(1.018 \text { to } 1.075) \\
p=0.001\end{array}$ \\
\hline Being hampered by disability, etc. & Not included & $\begin{array}{c}1.067 \\
(1.033 \text { to } 1.103) \\
p<0.001\end{array}$ & $\begin{array}{c}1.034 \\
(0.996 \text { to } 1.074) \\
p=0.08\end{array}$ \\
\hline Standardized odds ratios & 1.163 & 1.119 & $\begin{array}{l}1.127 \\
1.060\end{array}$ \\
\hline Controls & Included & Included & Included \\
\hline $\begin{array}{l}\text { Unweighted voters } \\
\text { Weighted voters }\end{array}$ & $\begin{array}{l}192,896 \\
188,478\end{array}$ & $\begin{array}{l}192,896 \\
188,478\end{array}$ & $\begin{array}{l}192,896 \\
188,478\end{array}$ \\
\hline Nagelkerke $R^{2}$ & 0.224 & 0.224 & 0.224 \\
\hline
\end{tabular}

odds ratio [OR] for each unit: $1.059,95 \%$ CI, 1.034 1.084, $p<0.001$; Table 1, Column 1). Meanwhile, a voter whose daily activities were hampered "a lot" by health problems had $14 \%$ greater odds of voting for a right-wing populist party than someone who was not constrained by such conditions (Model 2; OR $=1.067$, 95\% CI, 1.033-1.103, $p<0.001$; Table 1, Column 2). When the measures are tested together, a voter with "very bad" health had $20 \%$ greater odds of voting for a right-wing populist party, while the other health measure no longer meets conventional levels of statistical significance (Model 3; for general health, OR = 1.046, $95 \%$ CI, 1.018-1.075, $p=0.001$; for hampered by disability, etc., $\mathrm{OR}=1.034,95 \% \mathrm{CI}, 0.996-1.074, p=$ 0.08; Table 1, Column 3).

Consistent with existing research, we find that many demographic, socioeconomic, and cultural characteristics also predict populist voting. Right-wing populist 
voters were more likely to be white, male, younger, and less educated than other voters. Manual (skilled and nonskilled) workers voted for right-wing populists more often than professionals and managers. On average, these voters lived in more rural places, were more likely to have been unemployed for long periods, and were more likely to be receiving government benefits. They felt more negatively about immigrants, were more mistrustful of national and international institutions, espoused more authoritarian values, and identified more as right-wing. However, they did not feel less economically secure nor had lower incomes than mainstream voters. The standardized magnitudes of these predictors suggest that health had a greater influence on voters than income, self-reported economic insecurity, and living in rural areas, among other measures (Figures A.1-A.3). Meanwhile, they suggest that health had a smaller influence on voters than gender, education, and attitudes toward immigrants.

Neither dissatisfaction with life as a whole nor dissatisfaction with the country's health system predicted voting for right-wing populist parties. These findings suggest that voters distinguished their health status from general life satisfaction, which minimizes the concern that self-reported health might merely act as a proxy for a voter's satisfaction with life. Similarly, perceptions of health status appear to influence political decision making independently of experiences with and attitudes about a country's medical and public health infrastructure.

\section{Robustness}

The relationship between self-reported health and right-wing populist voting was robust to a variety of sensitivity analyses. The associations are retrieved when we respecify the health measures as dichotomous (Model 1, OR = 1.072 [1.027-1.118], $p=0.002$; Model 2, OR $=1.077$ [1.032-1.124], $p<0.001$; and Model 3, OR gen. $_{\text {. }} 1.048$ [0.999-1.098], $p=0.05$, and $\mathrm{OR}_{\text {hamp. }}=1.055$ [1.006-1.106], $\left.p=0.03\right)$ (Table A.8). Given the well-established association between poor health and nonvoting, we estimated a multinomial probit model with a polytomous outcome (mainstream voting, right-wing populist voting, and nonvoting). The association between poorer self-reported health and right-wing populist voting is robust to the inclusion of nonvoters. We also retrieve the relationship between poorer health and nonvoting identified in the literature (Table A.9). Next, we tested the robustness of our findings by sequentially introducing the controls in our fully specified models (Tables A.10-A.12). The direction and statistical significance of the association remain stable across these specifications, mitigating concerns about posttreatment bias.

To address survivor bias-whereby mainstream voters may die younger than right-wing populist voters and bias the observed association - we stratify our sample into three age groups and find that the association is preserved among younger voters (Tables A.13-A.15). The association also manifests in both pre- and post2008 periods (Tables A.16-A.17), suggesting that the relationship was not an artifact of the Great Recession. Similarly, it persists when county-year controls for GDP growth, life expectancy, health inequality, percentage of government expenditure on health, and out-of-pocket spending on health are included (Table A.18). Our findings are also robust to the inclusion of populationsize weights and countries that lacked populist parties during the study period, such as Ireland and Portugal (Tables A.19-A.20). Last, the continent-wide association remains unchanged after a one-by-one exclusion of each country, mitigating the concern that the observed relationship is driven by any single country (Table A.21).

\section{DISCUSSION}

Our findings suggest that a voter's perception of healthrelated vulnerability - beyond economic and cultural vulnerabilities-may be fueling right-wing populist support. This finding builds on research that has identified economic and cultural vulnerability as contributing to recent right-wing populist successes. Our models tested two distinct measures of health as proxies for health vulnerability: subjective general health and being hampered in daily activities by health problems. Their association with right-wing populist voting was robust to the inclusion of demographic, socioeconomic, and cultural controls. The results also suggest that the magnitude of this association may be comparable to that of some socioeconomic factors.

We had hypothesized that health vulnerability contributes to frustrations with the political status quo, not unlike how other vulnerabilities of a voter's economic and cultural position could feed an antiestablishment sentiment (Algan et al. 2017; Hochschild 2016; Inglehart and Norris 2016; Laclau 2005; Mudde 2007; Rodrik 2018; Smith and Hanley 2018). That is, illness inspires grievances with societal structures, driving voters to seek out political parties that promise to restructure them. Our findings complement work that has documented the association of declining community health with populist voting but at the individual level (Bilal, Knapp, and Cooper 2018; Bor 2017; Goodwin et al. 2018; Koltai et al. 2019; Wasfy, Stewart, and Bhambhani 2017).

Self-reported health measures reliably and costeffectively estimate "true" health status (Kaplan and Baron-Epel 2003). They have been shown to predict mortality in cohort studies with up to 25 years of followup (Idler and Benyamini 1997; Lorem et al. 2020); correlate with symptoms, disease diagnoses, and physicians' ratings of health status (Larue et al. 1979); and, to some degree, capture health as a positional good relative to a person's healthier neighbors (Eriksson, Undén, and Elofsson 2001). Meanwhile, research has shown that health is intimately linked to a person's social, economic, and political context (Woolf and Braveman 2011) and that it is associated with their perception of their social standing (Ostrove et al. 2000). It is, therefore, conceivable that economic and cultural factors could mediate the relationship between 
health status and right-wing populist voting. Because including mediators in a model can introduce bias, we showed that our results were robust to the inclusion of socioeconomic and cultural measures as controls as well as to their exclusion as potential posttreatment variables. As a result, our findings suggest that health vulnerability shapes right-wing populist sentiment beyond the influence of other individual-level factors already identified in the literature.

These results may generalize to other stable democracies. For example, in the U.S., perceptions of health status and health policy are even more tightly tied to socioeconomic inequities and political identity than in Europe (Hero, Zaslavsky, and Blendon 2017; Kirzinger et al. 2017). Indeed, as mentioned earlier, other researchers have observed a relationship between health and voting in the U.S. at the population level. However, the lack of universal health insurance and a robust safety net may mean that mainstream parties can better differentiate themselves along the health dimension, limiting the ability of right-wing populists to appeal to voters in poorer health. Moreover, detecting this relationship at the individual level in the U.S. might be more challenging. In a parliamentary system, voters can select parties that closely reflect their own ideologies, less so in a two-party, candidate-driven system.

Last, we turn our attention to implications for policy makers and health professionals. Many right-wing populists in Europe and the U.S. propose to dismantle public health systems (Pavolini et al. 2018). If mainstream parties accommodate these proposals and voters attribute the resulting deterioration in their health to the mainstream, the relationship we identified might be bolstered. If, however, voters attribute a deterioration in their health to the right-wing populist parties, as might happen if right-wing populists become mainstream, our proposed relationship might weaken (Meguid 2005). While the mechanism proposed in this paper remains too preliminary for specific policy recommendations, any relationship between health and political activity should train our attention on health inequities and their consequences. Support for policies designed to enhance public health infrastructure, improve access to medical care, and reduce socioeconomic inequality could affect not only well-being but also the political landscape.

Meanwhile, we discourage dismissing populist voters as irrational or irresponsible. To them, support for parties outside the mainstream reflects democratic accountability at work, whereby parties that don't serve their needs are punished for their poor performance. Thoughtful proposals that serve disaffected voters could allow mainstream parties to reengage their attention.

\section{Limitations and Future Directions}

We must consider the potential for reverse causality in this setting. That is, could voting for a right-wing populist party worsen a voter's self-reported health? We believe that this concern is minimized for a few reasons. If a voter's preferred candidate had come into office, it is unlikely that sufficient time would have passed between the election and the fielding of the ESS for structural changes that damage health to have been implemented. Alternatively, if their preferred candidate lost, dissatisfaction with the outcome of the election might negatively affect their self-perceptions. However, if it influenced their perceived health, we might also expect it to influence their satisfaction with life as a whole, and right-wing populist voters were no less satisfied with their lives than mainstream voters in our models. Lastly, communitylevel analyses indicate that changes in health status have predated surges in populist support (Bilal, Knapp, and Cooper 2018; Bor 2017; Koltai et al. 2019).

The serial cross-sectional design of this study cannot establish causality. Moreover, the ESS's limited measures cannot parse the intricacies of the experiences of illness and disability, nor can they distinguish whether absolute or positional changes in health are driving right-wing populist support. Also, self-evaluations of health may vary within countries over time. To test the mechanism more precisely, future research might correlate longitudinal changes in health status with political attitudes. For example, we might capture voters just after major injuries or chronic disease diagnoses and follow their voting behavior over time. At present, few large- $N$ datasets include both political and health outcomes, complicating the study of their relationship at the individual level. Given the influence of political and social structures on health - and vice versa-we encourage more surveys to track both together.

\section{SUPPLEMENTARY MATERIALS}

To view supplementary material for this article, please visit http://dx.doi.org/10.1017/S0003055421000265.

\section{DATA AVAILABILITY STATEMENT}

Replication files are available at the American Political Science Review Dataverse: https://doi.org/10.7910/ DVN/LIXQUW.

\section{ACKNOWLEDGMENTS}

We thank Mark Dincecco, Sarah E. Gollust, Scott L. Greer, Ronald Inglehart, Pauline Jones, Paula M. Lantz, Walter Mebane, and Atheendar S. Venkataramani for their helpful feedback on the project. We also extend our gratitude to Juli Highfill for overseeing the thesis from which this paper grew.

\section{CONFLICT OF INTEREST}

The authors declare no ethical issues or conflict of interest in this research.

\section{ETHICAL STANDARDS}

The authors affirm this research did not directly involve human participants. 


\section{REFERENCES}

Algan, Yann, Sergei Guriev, Elias Papaioannou, and Evgenia Passari. 2017. "The European Trust Crisis and the Rise of Populism.” Brookings Papers on Economic Activity 2017 (2): 309-400.

Bilal, Usama, Emily A. Knapp, and Richard S. Cooper. 2018. "Swing Voting in the 2016 Presidential Election in Counties Where Midlife Mortality Has Been Rising in White Non-Hispanic Americans." Social Science \& Medicine 197 (January): 33-8.

Bor, Jacob. 2017. "Diverging Life Expectancies and Voting Patterns in the 2016 US Presidential Election." American Journal of Public Health 107 (10): 1560-62.

Buunk, Bram P., Frederick X. Gibbons, and A. Buunk. 2013. Health, Coping, and Well-being: Perspectives from Social Comparison Theory. Hove, UK: Psychology Press.

Eriksson, Ingeborg, Anna-Lena Undén, and Stig Elofsson. 2001. "Selfrated Health. Comparisons between Three Different Measures. Results from a Population Study." International Journal of Epidemiology 30 (2): 326-33.

Goldthorpe, John H., Catriona Llewellyn, and Clive Payne. 1980. Social Mobility and Class Structure in Modern Britain. 2nd ed. Oxford: Clarendon Press.

Gollust, Sarah E., and Jake Haselswerdt. 2019. "Introduction Health and Political Participation: Advancing the Field." Journal of Health Politics, Policy and Law 44 (3): 341-48.

Goodwin, James S., Yong-Fang Kuo, David Brown, David Juurlink, and Mukaila Raji. 2018. "Association of Chronic Opioid Use with Presidential Voting Patterns in US Counties in 2016." JAMA Network Open 1 (2): e180450-e180450.

Hero, Joachim O., Alan M. Zaslavsky, and Robert J. Blendon. 2017. "The United States Leads Other Nations in Differences by Income in Perceptions of Health and Health Care." Health Affairs 36 (6): 1032-40.

Hochschild, Arlie Russell. 2016. Strangers in Their Own Land: Anger and Mourning on the American Right. New York: The New Press.

Idler, Ellen L., and Yael Benyamini. 1997. "Self-rated Health and

Mortality: A Review of Twenty-seven Community Studies." Journal of Health and Social Behavior 38 (1): 21-37.

Inglehart, Ronald F., and Pippa Norris. 2016. "Trump, Brexit, and the Rise of Populism: Economic Have-nots and Cultural Backlash." Social Science Research Network HKS Working Paper Series No. RWP16-026: 53.

Kaplan, Giora, and Orna Baron-Epel. 2003. "What Lies behind the Subjective Evaluation of Health Status?" Social Science \& Medicine 56 (8): 1669-76.

Kavanagh, Nolan M., Anil Menon, and Justin E. Heinze. 2021. "Replication Data for: Does Health Vulnerability Predict Voting for Right-wing Populist Parties in Europe?" Harvard Dataverse. Dataset. https://doi.org/10.7910/DVN/LIXQUW.

Kirzinger, Ashley, Bianca DiJulio, Bryan Wu, and Mollyann Brodie. 2017. "Kaiser Health Tracking Poll-August 2017: The Politics of ACA Repeal and Replace Efforts." Kaiser Family Foundation. August 11, 2017. https://www.kff.org/health-reform/poll-finding/ kaiser-health-tracking-poll-august-2017-the-politics-of-acarepeal-and-replace-efforts/.

Koltai, Jonathan, Francesco Maria Varchetta, Martin McKee, and David Stuckler. 2019. "Deaths of Despair and Brexit Votes:
Cross-local Authority Statistical Analysis in England and Wales." American Journal of Public Health 110 (3): 401-6.

Laclau, Ernesto. 2005. On Populist Reason. London: Verso.

Landwehr, Claudia, and Christopher Ojeda. 2021. "Democracy and Depression: A Cross-national Study of Depressive Symptoms and Nonparticipation." American Political Science Review 115 (1): 323-30.

Larue, Asenath, Lew Bank, Ussy Jarvik, and Monte Hetland. 1979. "Health in Old Age: How Do Physicians' Ratings and Self-ratings Compare?" Journal of Gerontology 34 (5): 687-91.

Lorem, Geir, Sarah Cook, David A. Leon, Nina Emaus, and Henrik Schirmer. 2020. "Self-reported Health as a Predictor of Mortality: A Cohort Study of Its Relation to Other Health Measurements and Observation Time." Scientific Reports 10 (1): 4886.

Martz, Erin, and Hanoch Livneh, eds. 2007. Coping with Chronic Illness and Disability: Theoritical, Empirical, and Clinical Aspects. New York: Springer.

Meguid, Bonnie M. 2005. "Competition between Unequals: The Role of Mainstream Party Strategy in Niche Party Success." American Political Science Review 99 (3): 347-59.

Mudde, Cas. 2007. Populist Radical Right Parties in Europe. Cambridge: Cambridge University Press.

Norris, Pippa, and Ronald Inglehart. 2019. Cultural Backlash: Trump, Brexit, and Authoritarian Populism. New York: Cambridge University Press.

Nussbaum, Martha C. 2018. The Monarchy of Fear: A Philosopher Looks at Our Political Crisis. 1st ed. New York: Simon \& Schuster.

Oesch, Daniel. 2008. “Explaining Workers' Support for Right-wing Populist Parties in Western Europe: Evidence from Austria, Belgium, France, Norway, and Switzerland.” International Political Science Review 29 (3): 349-73.

Ostrove, Joan M., Nancy E. Adler, Miriam Kuppermann, and A. Eugene Washington. 2000. "Objective and Subjective Assessments of Socioeconomic Status and Their Relationship to Self-rated Health in an Ethnically Diverse Sample of Pregnant Women." Health Psychology 19 (6): 613-18.

Pacheco, Julianna, and Jason Fletcher. 2015. "Incorporating Health into Studies of Political Behavior: Evidence for Turnout and Partisanship." Political Research Quarterly 68 (1): 104-16.

Pavolini, Emmanuele, Ellen Kuhlmann, Tuba I. Agartan, Viola Burau, Russell Mannion, and Ewen Speed. 2018. "Healthcare Governance, Professions and Populism: Is There a Relationship? An Explorative Comparison of Five European Countries." Health Policy 122 (10): 1140-48.

Rodrik, Dani. 2018. "Populism and the Economics of Globalization." Journal of International Business Policy 1 (June): 12-33.

Schur, Lisa, Todd Shields, Douglas Kruse, and Kay Schriner. 2002. "Enabling Democracy: Disability and Voter Turnout." Political Research Quarterly 55 (1): 167-90.

Smith, David Norman, and Eric Hanley. 2018. "The Anger Games: Who Voted for Donald Trump in the 2016 Election, and Why?" Critical Sociology 44 (2): 195-212.

Wasfy, Jason H., Charles Stewart, and Vijeta Bhambhani. 2017. "County Community Health Associations of Net Voting Shift in the 2016 U.S. Presidential Election." PLoS ONE 12 (10): 0185051.

Woolf, Steven H., and Paula Braveman. 2011. "Where Health Disparities Begin: The Role of Social and Economic DeterminantsAnd Why Current Policies May Make Matters Worse." Health Affairs 30 (10): 1852-59. 